\title{
Sensing Properties of Ga-doped ZnO Nanowire Gas Sensor
}

\author{
Sang Yeol Lee ${ }^{\dagger}$ \\ Department of Semiconductor Engineering, Cheongju University, Cheongju 360-764, Korea
}

Received March 17, 2015; Revised March 20, 2015; Accepted March 25, 2015

\begin{abstract}
Pure $\mathrm{ZnO}$ and $\mathrm{ZnO}$ nanowires doped with 3 wt.\% Ga ('3GZO') were grown by pulsed laser deposition in a furnace system. The doping of $\mathrm{Ga}$ in $\mathrm{ZnO}$ nanowires was analyzed by observing the optical and chemical properties of the doped nanowires. The diameter and length of nanowires were under $200 \mathrm{~nm}$ and several $\mu \mathrm{m}$, respectively. Changes of significant resistance were observed and the sensitivities of $\mathrm{ZnO}$ and $3 \mathrm{GZO}$ nanowires were compared. The sensitivities of $\mathrm{ZnO}$ and $3 \mathrm{GZO}$ nanowire sensors measured at $300^{\circ} \mathrm{C}$ for $1 \mathrm{ppm}$ of ethanol gas were $97 \%$ and $48 \%$, respectively.
\end{abstract}

Keywords: Metal-oxide-semiconductor field-effect transistor, Lateral asymmetric channel doping, Transconductance, On-state drain current, Channel-hot-carrier degradation

\section{INTRODUCTION}

$\mathrm{ZnO}$-based nanostructures have attracted much attention because of their exquisite sensitivity and fast response to the surrounding environment [1-5]. In recent years, n-type doping control of $\mathrm{ZnO}$ nanowires (NWs) has attracted great attention. Especially, ZnO-based NWs are particularly useful due to their manageable conductance with doping control in addition to their large length-to-diameter and surface-to-volume ratio versus bulk and films of $\mathrm{ZnO}$ [6]. The electrical conductivity of $\mathrm{ZnO}$ can change dramatically by the presence of reactive gases in the air; there have been many reports on the application of semiconducting metal oxides as gas sensors due to their small dimensions, low cost, and high compatibility with microelectronic processing[7,8]. Furthermore, ZnO-based semiconductor materials have received much attention due to their excellent electrical and optical characteristics, such as large band gap energy, of 3.37 $\mathrm{eV}$, and large exciton binding energy, of $60 \mathrm{meV}$, at room temperature (RT) [9].

To date, in room temperature operation, most gas sensors still face difficulties in getting a high response to volatile organic

${ }^{\dagger}$ Author to whom all correspondence should be addressed:

E-mail: sylee@cju.ac.kr

\section{Copyright (C2015 KIEEME. All rights reserved.}

chemicals (VOCs), such as ethanol, acetone, methanol, and LPG. Furthermore, there are few reports on the study of the gas-sensing properties of Ag-doped $\mathrm{ZnO} \mathrm{NW}$ to ethanol. Some reports have shown possible room temperature operation for ethanol using $\mathrm{ZnO}$ NWs [10]. To obtain high responses and selectivity, different approaches, such as microstructure control, doping, and changing operating temperatures have been adopted to modify the sensing properties of semiconductor metal oxide gas sensors $[11,12]$. It is known that the sensing mechanism is based on the surface reaction of the nanostructure with the exposed gas (adsorption and desorption of the test gas molecules). As adsorption is a surface effect, one can increase the adsorption of gas molecules by decorating with nanoparticles or doping with an element that has a stronger chemical affinity for that particular gas molecule. Doping in a NW can create defects and these defects play a role as preferential adsorption sites for gas molecules, which can help to sense pollutant gases at lower temperatures [13]

In this study, $\mathrm{ZnO}$ nanowires, undoped and doped with $3 \mathrm{wt} . \%$ $\mathrm{Ga}$, were grown using pulsed laser deposition in a furnace (PLDF) and nanowire gas sensors were fabricated. The sensitivity ranges of ethanol gas sensors varied depending on the amount of Ga dopant due to different carrier concentration in the $\mathrm{ZnO}$ NWs. The ethanol gas sensing properties of these materials were characterized using a self-assembled sensing analyzer. The effect of Ga content on gas sensing properties to ethanol for high sensitivity and high selectivity was investigated in detail. The sensing 
mechanism of the gas sensor to ethanol is also discussed.

\section{EXPERIMENT DETAILS}

ZnO-based NWs were synthesized by a PLDF process on 20 $\AA$ Au film as a catalyst on sapphire substrates. The PLDF has a target rotating system, ensuring homogeneous target ablation. $\mathrm{ZnO}$ and 3GZO targets were used to fabricate the NWs under optimized conditions. The diverse $\mathrm{ZnO}$-based NWs were grown in a PLDF at a temperature of $800^{\circ} \mathrm{C}$ with Ar carrier gas (Fig. 1). During the deposition, the Ar gas flow rate was fixed at $90 \mathrm{sccm}$ and the pressure inside the quartz tube was maintained at 1.2 Torr. A $\mathrm{KrF}$ excimer laser $(248 \mathrm{~nm})$, operating at a pulse repetition rate of $10 \mathrm{~Hz}$, was focused on to a pristine $\mathrm{ZnO}$ target for the growth. The energy density of the laser was set to $1.2 \mathrm{~J} / \mathrm{cm}^{2}$, and the shot area on the target surface was $0.042 \mathrm{~cm}^{2}$. The morphology of asgrown samples was studied by field emission scanning electron microscopy (FE-SEM), operated at $20 \mathrm{kV}$. Energy-dispersive Xray spectroscopy (EDX) analysis of a single NW was conducted to analyze the chemical composition of the doped NWs. The growth time of the ZnO-based NWs was 30 min.

For the fabrication of the ZnO-based sensors, we spread out NWs on Si substrates after cleaning. Soon after photolithography, the substrates were developed. For the ohmic contact, metal electrodes, consisting of Ti $(20 \mathrm{~nm})$ and $\mathrm{Au}(150 \mathrm{~nm})$, were deposited by e-beam/thermal evaporator and patterned by a liftoff process to form contact pads on NWs. The sensitivity of the module was measured with the concentration of the ethanol gas at $1 \mathrm{ppm}$ in the self-designed gas chamber at $300^{\circ} \mathrm{C}$.

\section{RESULTS AND DISCUSSION}

Figures 2(a-d) show the controlled morphology of the $\mathrm{ZnO}$ and 3 GZO NWs and EDX spectra. SEM with EDX (SEM/EDX) is an electron probe microanalysis method that has been used extensively to characterize the size, morphology, and elemental composition of samples. The NWs have thread-like shapes and a Au nanoparticle at its end is clearly observed. It is understood that the nanoparticle is an Au catalyst that initiates the growth of the NWs by HWPLD, one of the vapor-liquid-solid (VLS) mechanisms. The catalyst can be identified based on the fact that the tips are brighter than the stem parts of the NWs. As can be seen in the figure, the orientation and the distribution of the NWs are random, with a diameter of $\sim 100 \mathrm{~nm}$ and the length of $\sim 1 \mu \mathrm{m}$. ZnO-based NWs were synthesized with $\mathrm{ZnO}$ targets by PLDF. Figures 2(a) and (c) show the top view of FE-SEM images of ZnObased NWs with pure $\mathrm{ZnO}$ and $3 \mathrm{GZO}$ with a $20 \AA \mathrm{Au}$ film as a catalyst. As shown in Fig. 2, many random-direction $\mathrm{ZnO}$-based NWs with a mean diameter of $\sim 70 \mathrm{~nm}$ and an average length of $\sim 9 \mu \mathrm{m}$ were obtained at $800^{\circ} \mathrm{C}$.

The EDX analysis yielded reasonably accurate quantitative results featuring all the elements present in the test compounds: $\mathrm{C}, \mathrm{O}, \mathrm{N}, \mathrm{Na}, \mathrm{S}, \mathrm{Al}, \mathrm{Si}$, and $\mathrm{Cl}$. Furthermore, the carbon film has a very low backscattered electron (BSE) yield compared with that from the particles. Thus, in BSE mode, the particle image can be observed with very high contrast. This improves quality and speed of the automated mapping of particles by SEM prior to EDX analysis [4]. Figure 2 shows a backscatter electron image of the morphology and surface composition of the fractured surface of a specimen, which corresponds to the EDX spectrum. It can be seen that there is a clear $\mathrm{ZnO}$ and Ga-related peak with some unidentified peaks at 1.5 and $2.0 \mathrm{keV}$, probably from the substrate. The EDX spectrum revealed the presence of $\mathrm{Zn}$ and Ga elements. PLDF is a well-established growth method for oxide

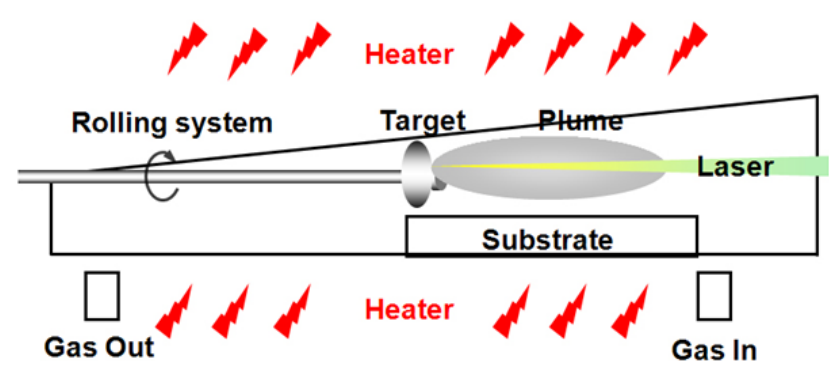

Fig. 1. Pulsed laser deposition in a furnace system for the fabrication of the doped $\mathrm{ZnO}$ NWs.

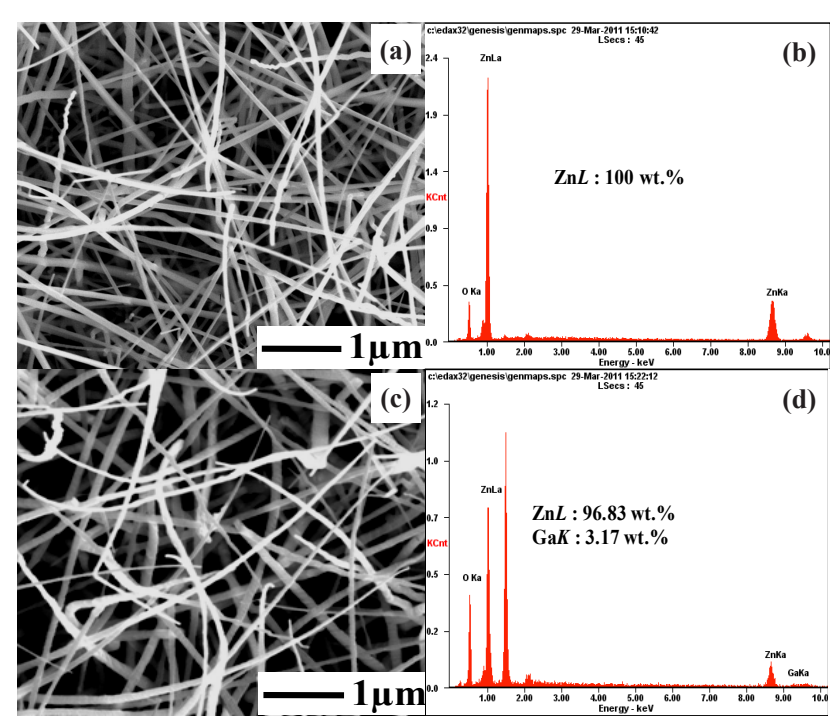

Fig. 2. Top view of FE-SEM image and EDX data of (a), (b) $\mathrm{ZnO}$ and (c), (d) 3 GZO.

thin films and nanostructures of high structural quality. Thus, PLDF is a simple synthesis process and only target control can give effective doping in the $\mathrm{ZnO}$ NWs. Such a result indicates that the impurities were doped well in the ZnO-based NWs.

It is important to realize highly functional NW-field effect transistor (FET) devices for the optimization of sensing properties. NW-FETs also have many advantages to enhance the sensitivity and selectivity for different gas species. It has been reported that $\mathrm{ZnO}$ NW-FET show remarkable n-type FET characteristics $[14,15]$. The transport properties of our single NW-FET device exhibited excellent $n$-type characteristics with strong gate control. The NW-FET sensors shown in Figure 3 were used for the detection of ethanol gas at $300^{\circ} \mathrm{C}$. The system was purged with $\mathrm{N} 2$ gas to remove excess oxygen species from the surface of the NW in the chamber. The sensitivity of the ZnO and 3GZO NWs sensor for $1 \mathrm{ppm}$ at $300^{\circ} \mathrm{C}$ ethanol gas is shown in Fig. 4. The sensitivity, defined as $\left(\mathrm{R}_{\mathrm{g}}-\mathrm{R}_{\mathrm{a}}\right) / \mathrm{R}_{\mathrm{a}}$, where $\mathrm{Rg}$ and $\mathrm{Ra}$ is the electrical resistance in ethanol gas and dry air, respectively, changes with different dopants in ZnO-based nanowire FETs. The sensitivities of the sensors were $97 \%$ and $48 \%$ for $\mathrm{ZnO}$, and $3 \mathrm{GZO}$, respectively. The main effects of doping in oxide semiconducting NWs are the changes in electronic conductivity and the introduction of defects into the NWs. These factors play important roles in changing the sensitivity in NW sensors. Defects within the crystal structure can improve the adsorption of gas molecules on the NW surface and the change in the conductivity will change the position of the Fermi level in the energy band diagram, which governs the electronic transportation between gas molecule and 
NW material [16]

If $\mathrm{ZnO} \mathrm{NW}$ was doped with the same quantity, it would be different in resistance. The resistance of GZO might be more conductive than $\mathrm{ZnO}$, due to a difference in the quantity of carriers. Thus, sensitivity can also be changed proportionally to the formula of the sensitivity's definition. In fact, oxygen adsorption plays an important role in the electrical properties of the doped $\mathrm{ZnO}$ nanomaterial with microstructures. Oxygen ion adsorption removes the conduction electrons and increases the resistance of $\mathrm{ZnO}$. Reactive oxygen species, such as $\mathrm{O}^{-}, \mathrm{O}^{-}$and $\mathrm{O}^{-}$are adsorbed on the $\mathrm{ZnO}$ surface at elevated temperature, and the amounts of such chemisorbed oxygen species depend strongly on temperature. At low temperatures, $\mathrm{O} 2$ is chemisorbed, while at high temperatures, $\mathrm{O}^{-}$and $\mathrm{O}^{-}$are chemisorbed, and the $\mathrm{O} 2$ disappears rapidly. The whole of the oxygen adsorption process can be described by the following formulae [17]:

$$
\begin{aligned}
& \mathrm{O}_{2 \text { (gas) }} \leftrightarrow \mathrm{O}_{2 \text { (adsorbed) }} \\
& \mathrm{O}_{2 \text { (adsorbed) }}+\mathrm{e}^{-} \leftrightarrow \mathrm{O}_{2 \text { (adsorbed) }} \\
& \mathrm{O}_{2 \text { (adsorbed) }}{ }^{2-}+\mathrm{e}^{-} \leftrightarrow 2 \mathrm{O}_{\text {(lattice) }}{ }^{2-}
\end{aligned}
$$

In addition, the electrical detection of any chemical species is dependent on the surface reactions between the NWs and the chemical molecules. The ethanol sensing mechanism of this ZnO-based gas sensor can be described as follows: [18]

$$
\mathrm{CH}_{3} \mathrm{CH}_{2} \mathrm{OH}_{\text {(adsorbed) }}+6 \mathrm{O}_{\text {(adsorbed) }} \rightarrow 2 \mathrm{CO}_{2}+3 \mathrm{H}_{2} \mathrm{O}+6 \mathrm{e}^{-}
$$

The sensitivity and sensing window of ZnO-based NW gas sensors can be expanded by different doping in the NWs. The ZnObased nanowires were fabricated using a self-designed PLDF instrument to compare the sensing functions with various impurities. The conductivity and ethanol gas sensitivity of the sensors doped with different impurities were investigated. In the case of the undoped $\mathrm{ZnO}$ and the $3 \mathrm{GZO} \mathrm{NW}$ gas sensor, measured sensitivities were $97 \%$ and $48 \%$, when the sensor was operated at $300^{\circ} \mathrm{C}$ with $1 \mathrm{ppm}$ of ethanol gas. The response time and recovery time were also fair. Consequently, we can easily control the sensitivity for the same gas by using different concentrations of Ga and selectivity is also expected to change with doping materials. The sensitivity ranges of ethanol gas sensors could be expanded depending on the amount of Ga dopant due to the control of different carrier concentration in the $\mathrm{ZnO}$ NWs.

\section{CONCLUSIONS}

In summary, the sensitivity and sensing window of $\mathrm{ZnO}$-based NW gas sensors can be expanded by different doping in the NWs. The ZnO-based nanowires were fabricated using a self-designed PLDF instrument to compare the sensing functions with various impurities. The conductivity and ethanol gas sensitivity of the sensors doped with different impurities were investigated. In the case of undoped $\mathrm{ZnO}$ and the $3 \mathrm{GZO} \mathrm{NW}$ gas sensor, measured sensitivities were $97 \%$ and $48 \%$ when the sensor was operated at $300^{\circ} \mathrm{C}$ with $1 \mathrm{ppm}$ of ethanol gas. The response time and recovery time were also fair. Consequently, we can easily control the sensitivity for the same gas by using different concentrations of Ga
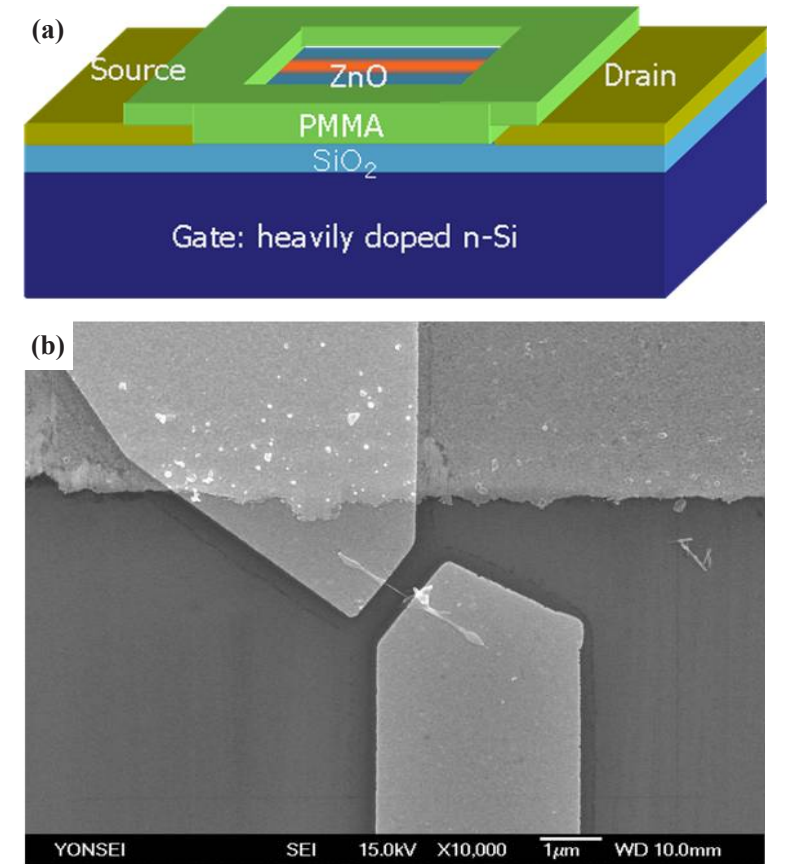

Fig. 3. (a) Schematic diagram of nanowire field-effect transistor and (b) optical image of implemented nanowire FET.
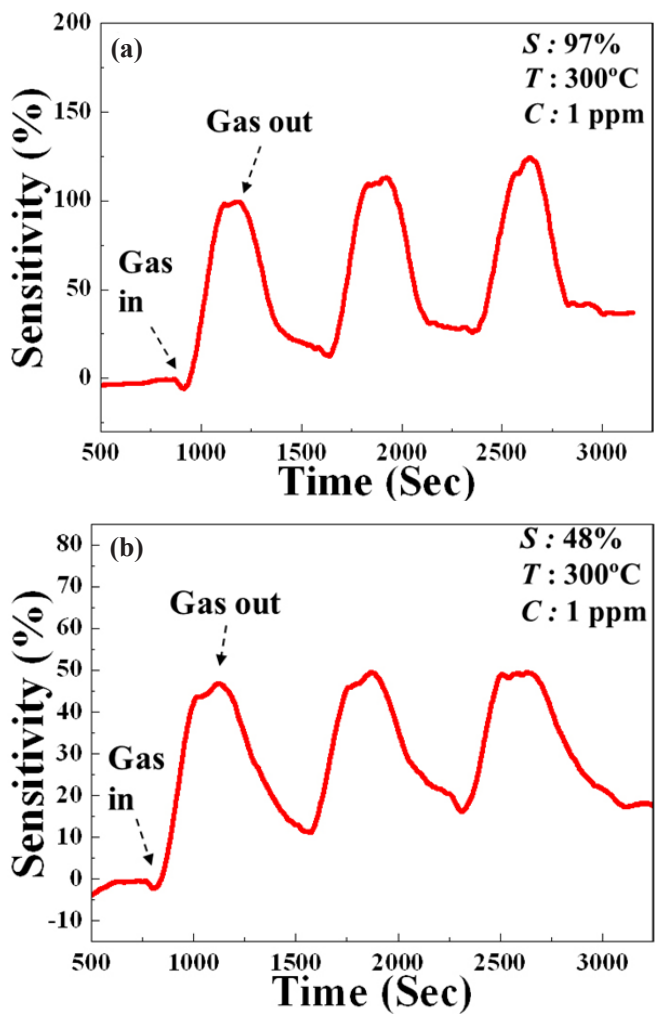

Fig. 4. Change in sensitivity on exposure to $1 \mathrm{ppm}$ of ethanol gas, measured at $300^{\circ} \mathrm{C}$ for (a) pure $\mathrm{ZnO}$ and (b) $3 \mathrm{GZO}$.

and selectivity is also expected to change with doping materials.

A plausible explanation on the improved sensing behavior in the doped NWs compared to undoped NWs is related to the defects created by doping. Doping in NWs can generate defects, such as oxygen vacancies, metal interstitials, and surface de- 
fects, and these defects play a vital role in the sensing of ethanol gas. The obtained dependencies of the sensitivity for differently doped $\mathrm{ZnO} \mathrm{NW}$-based sensors are discussed considering the undoped and Ga-doped. Experimental data confirm the prospects of thin $\mathrm{ZnO}$ NWs as active elements for nanoscale sensors operating at room temperature. The sensing mechanisms of $\mathrm{ZnO}$ NWs were determined. These results demonstrate that ZnO NWs can be used as a gas-sensing material for fabricating highly sensitive gas sensors and are expected to find wide applications in various complex moist gases for the quick detection of poisonous and inflammable gases.

\section{REFERENCES}

[1] Z. L. Wang, Ann. Rev. Mater. Res., 55, 159 (2004),

[2] A. Kolmakov and M. Moskovits, Ann. Rev. Mater. Res., 34, 151 (2004). [DOI: http://dx.doi.org/10.1146/annurev. matsci.34.040203.112141]

[3] J. G. Lu, P. Chang, and Z. Fan, Mater. Sci. Eng. R, 52, 49 (2006). [DOI: http://dx.doi.org/10.1016/j.mser.2006.04.002].

[4] E. S. Snow, F. K. Perkins, and J. A. Robinson, Chem. Soc. Rev., 35, 790 (2006). [DOI: http://dx.doi.org/10.1039/b515473c].

[5] P. C. Chen, G. Shen, and C. Zhou, IEEE Trans. Nanotech., 7, 668 (2008). [DOI: http://dx.doi.org/10.1109/TNANO.2008.2006273].

[6] K. W. Kim, Y. W. Song, S. P. Chang, I. H. Kim, S. S. Kim, and S. Y. Lee, Thin Solid Films, 518, 1190 (2009). [DOI: http://dx.doi. org/10.1016/j.tsf.2009.03.229].

[7. N. O. Korsunska, L. V. Borkovska, B. M. Bulakh, L. Yu. Khomenkova, V. I. Kushnirenko, and I. V. Markevich, J. Lumin., 102/103, 733 (2003). [DOI: http://dx.doi.org/10.1016/S00222313(02)00634-8].
[8] K. Vanheusden, W. L. Warren, C. H. Seager, D. R. Tallant, J. A. Voigt, and B. E. Gnade, J. Appl. Phys., 79, 7983 (1996). [DOI: http://dx.doi.org/10.1063/1.362349].

[9] J. Zhong, S. Muthukumar, Y. Chen, Y. Lu, H. M. Ng, W. Jiang, and E. L. Garfunkel, Appl. Phys. Lett., 83, 3401 (2003). [DOI: http:// dx.doi.org/10.1063/1.1621729].

[10] D. H. Zhang, Z. Q. Liu, C. Li, T. Tang, X. L. Liu, S. Han, B. Lei, and C. W. Zhou, Nano Lett., 4, 1919 (2004). [DOI: http://dx.doi. org/10.1021/nl0489283].

[11] D. H. Zhang, C. Li, X. L. Liu, S. Han, T. Tang, and C. W. Zhou, Appl. Phys. Lett., 83, 1845 (2003). [DOI: http://dx.doi. org/10.1063/1.1604194].

[12] C. Li, D. H. Zhang, B. Lei, S. Han, X. L. Liu, and C. W. Zhou, J. Phys. Chem. B, 107, 12451 (2003). [DOI: http://dx.doi. org/10.1021/jp0361531].

[13] M. W. Ahn, K. S. Park, J. H. Heo, J. G. Park, D. W. Kim, K. J. Choi, J. H. Lee, and S. H. Hong, Appl. Phys. Lett., 93, 263103/1 (2008).

[14] W. F. Zhang, Z. B. He, G. D. Yuan, J. S. Jie, L. B. Luo, X. J. Zhang, Z. H. Chen, C. S. Lee, W. J. Zhang, and S. T. Lee, High Performance, Appl. Phys. Lett., 94, 123103/1 (2009).

[15] W. Zhang, J. Jie, Z. He, S. Tao, X. Fan, Y. Zhou, G. Yuan, L. Luo, W. Zhang, C. Lee, and S. Lee, Appl. Phys. Lett., 92, 153312/1 (2008).

[16] M. W. Ahn, K. S. Park, J. H. Heo, J. G. Park, D. W. Kim, K. J. Choi, J. H. Lee, and S. H. Hong, Appl. Phys. Lett., 93, 263103/1 (2008).

[17] T. J. Hsueh, C. L. Hsu, S. J. Chang, and I. C. Chen, Sens. Actuators B: Chem., 126, 473 (2007). [DOI: http://dx.doi.org/10.1016/ j.snb.2007.03.034].

[18] Z. Yanga, Y. Huang, G. Chen, Z. Guoc, S. Cheng, and S. Huange, Sensors and Actuators B, 140, 549 (2009). [DOI: http://dx.doi. org/10.1016/j.snb.2009.04.052]. 